\title{
Diversity in the Educational Process: Basis for a Conceptual Proposal
}

\section{La diversidad en los procesos educativos: bases para una propuesta conceptual}

\author{
Dora Hernández Vargas' \\ Universidad Nacional \\ Research Center for Education and Teaching (CIDE) \\ Basic Education Division \\ Heredia, Costa Rica \\ dorahv@gmail.com \\ "I don't know if what I like about you are our differences or what we have in common. \\ Whether you like it or not, I enjoy both. \\ What we have in common comforts me, our \\ differences encourage me." \\ Joan Manuel Serrat
}

Received: May $7^{\text {th }}, 2007 \cdot$ Approved: June $12^{\text {th }}, 2007$

\begin{abstract}
The main thesis of this work is that the elements that raise difficulty with the diversity concept approach are the consequences that we derive from its recognition. And this recognition comes from pedagogy. After succinctly examining the importance of the idea of diversity in mainstream traditions of social philosophy, the author proposes the conceptual basis that from these ideological readings must direct the pedagogical approach to the concept.
\end{abstract}

Key words: Diversity; exclusion; inclusion; curriculum for diversity; pedagogy for diversity.

Resumen: La tesis principal de este trabajo es que lo que hace problemático el abordaje del concepto de diversidad son las consecuencias que derivemos de su reconocimiento. $Y$ este reconocimiento se hace desde la pedagogía. Luego de examinar, de forma sucinta, la trascendencia de la idea de diversidad en las principales tradiciones de la filosofía social, la autora propone las bases conceptuales que, desde estas lecturas ideológicas deben dirigir el abordaje pedagógico del concepto.

Palabras Claves: Diversidad; exclusión; inclusión; currículum para la diversidad; pedagogía para la diversidad

'Masters degree in Pedagogy with an emphasis in Diversity in the Educational Process. Experience in Music Education and professor of the Basic Education Division. Research Center and Education Professor, Universidad Nacional. 
URL: http://www.una.ac.cr/educare

CORREO: educare@una.cr

\section{Introduction}

As a student in the Masters in Pedagogy with an emphasis in diversity in the educational process of the Universidad Nacional, I would question the assumptions by which we analyzed the diversity concept. First, what should be understood by this concept? Is this a univocal concept? Or is this a concept that allows diverse interpretations? Second, was I conscious that the underlying diversity approach entailed pedagogical significance? If so, the questions were: Can we consider all students as diverse, or only those that are outside the norm? Faced with the questions that arise from the diversity concept, which aspects within the curriculum must be transformed? Is it possible to attend diversity with the framework of a common curriculum or do we need as many curriculums as cultures and persons that we attend pedagogically?

These concerns drove me to investigate the concept of diversity in the educational process, constructed in the Masters program. After encountering consensus by some and opposition by others, regarding the approach of the concept, I defined my conceptual basis that could serve as input for the construction of a conceptual proposal founded in a pedagogical vision of diversity. With this in mind I believed it was necessary to review the importance of the idea of diversity in mainstream traditions of social philosophy.

It is important to mention the reason of this review. It is evident that differences exist among human beings, sometimes a nuance and on other occasions bearing significant weight. Where then, if any, does the problematicity of the diversity concept lie?

In my opinion, this problematicity resides in its significance. In other words, what makes the diversity concept approach problematic are the consequences that we derive from its recognition. Of course, with regards to this work, the interest is the importance of the recognition of diversity in the educational process, and its ties with society. For this reason it is convenient to take a look at the main definitions that philosophy has provided regarding society.

This reveals the need to address the diversity concept from the perspective of society. The curriculum is not neutral. Freire has pointed out that education is a political stance, hence, the way diversity is addressed should also be political.

In the analysis of diversity in the educational process it is necessary to evaluate the transforming force of the education project or projects. It is imperative to recognize the school setting as an institution that substantively participates in the construction of its citizens, and the systematic analysis in which citizens participate in this process.

\section{The idea of diversity in the social philosophy traditions}

To be able to analyze the meaning of the diversity concept in the main social philosophy traditions we will adhere to the typology embraced by Sacristan (2002), which identified three 
main traditional thoughts that are classified as: a) Liberal democratic, b) Communitarianism, and c) Democratic republicanism.

\section{The idea of diversity in liberal democratic thinking}

For many, it is evident that not only one type of liberalism exists, but that under liberalism we can find many ideological venues, that range from liberal capitalists, the Chicago Boys to rationalism that criticizes the theorist of the open Society, defenders of the individual facing the capital oligopolies.

Even though there are differences, all forms of liberalism share common values, such as: individual priority over collective priority, formal equality among human beings, universalism, institutional neutrality when facing different beliefs, tolerance of diverse beliefs and the confidence that institutions can improve in character (Gray, cited by Sacristan, 2002).

From a liberal standpoint, diversity is the consequence of the individualization process. Individualization is understood as the quality of being and the possibility to be different from others, allowing freedom and autonomy of each person and acknowledging others, an essential requirement to live in society.

When asked: In liberalism, what is the essence of an individual? Liberalism's response is to appear individualized a priori as a condition, metaphysically essential, a characteristic pertaining to all human beings. The qualities of this abstract and universal individual are independent from their origin, their personal condition or their background (ethnic, gender, social class, etc.), because they constitute the foundation for an essential identity for the subjects, conceived as free, autonomous, with the capacity to choose (Sacristan, 2002).

Precisely, this possibility of humans to choose their being and their development is the foundation so that pluralism and liberal democracy can exist. In fact, correlated to the right to diversity, which is inherent to everyone, the others, mainly the State, are forced by a duty to respect and tolerate the diversity of the individual. Sacristan (2002) considers that the liberal stance towards pluralism (including cultural pluralism) is tolerant and egalitarian; it is not belligerent in the promotion of any option or set culture and that in the idea of being a form of life and expression corresponds to the private options to make these types of decisions.

According to this paradigm of being political, the State has resigned its authority to impose upon individuals a determined project of what happiness should look like, and above all, an anthropological ideal. With this resignation, they have also abdicated the promotion of a model lifestyle. Nevertheless, in spite of the neutrality that should characterize the liberal State, its politics admits certain cultural assimilations, because the State cannot exist without a common framework that encompasses all individuals. This is true according to Sacristan (2002), 
URL: http://www.una.ac.cr/educare

CORREO: educare@una.cr

even though pedagogy, within liberalism, has rested on four basic pillars: the construction and defense of the moral individual, the propagation of scientific rationality, tolerance towards others and the legitimation of social institutions.

The danger in approaching diversity from this way of thinking lies in conceiving it from the sole perspective of individual difference. This can lead us to the atomization of the curriculum. In this manner, the existence of a curriculum for every person is gladly accepted, customized to their particular needs and interests. If this were so, where do common bonds come in to play and how can there possibly exist a community project? Only individual projects could be built.

Furthermore, from this perspective, we are at risk of forgetting any collective difference. To approach diversity from individual diversity we forget cultural and linguistic differences. Suppose that the differences are natural and that diversity is a natural phenomenon, leaving aside a central element in this analysis: that diversity is a problem because relations of power or authority have made diversity turn into exclusion. This aspect will be further explained later.

\section{The idea of diversity in communitarian thinking}

In the same way we have observed liberalism, in communitarianism we can also find many ideological venues that range from political options characterized by conservatism to popular methods of doing politics.

Nevertheless, beyond any dissidence, our interest in communitarianism is their posture towards diversity and the cultural state, which is a common factor among all venues.

The communitarian thesis assumes culture as a "unifying element for human groups, and at the same time establishes the difference between these groups due to the same motive" (Sacristan 2002, pg. 181). This declaration establishes a substantial difference between liberalism and communitarianism. In liberalism thinking, diversity is a consequence of the options the individual adopts as his own; but for communitarianism diversity is a human condition received by the culture in which that person was born. In other words, what marks the difference, from the communitarian perspective, does not reside in the decisions made by the individual, but in the cultural group to which that person pertains, referred to as the cultural state.

As we can observe, for the different venues in communitarian thinking, diversity is a topic that should be approached from a multiculturalism perspective. This has implications of great stature for the education field, as Sacristan (2002) states, multiculturalism, as a variety of culture is undeniable, and furthermore, it is a project, an ideology and a world view.

As a part of this world view, the multiculturalism communitarians sustain that the existence of different communities must be recognized, which raises conflicts for the education field 
when these communities live within the same political and territorial settings. First, the most conservative positions in communitarianism aspire to build closed communities with regards to their traditions, and consequently with their exclusive educational programs. Other conservative derivations would choose to grant families the exclusive right regarding the education of their children, which could lead to extreme positions as that of parents claiming the right to resign the public school system and educate their children at home, with a domestic curriculum, in the strictest meaning of the word.

In the same manner, within the positions upheld by the multiculturalism communitarians that Sacristan (2002) describes as perspective relativisms, which are characterized by not admitting that, the practices and beliefs of one culture can be understood by another. This perspectivism considers that it is not possible to construct a common open curriculum that goes beyond the cultural boundaries of each community. In these circumstances they demand the dismantling of state education and claim the right of the cultural communities to develop their own curriculum project. According to Sacristan (2002), from these assumptions:

(...) the school will tend to organize itself as a micro-community that serves the community in which it is inserted, in accordance with the values of such community, restoring and affirming those values, providing each individual with references to obtain a clear identity based on the culture and moral values of the community. The teachers must be "aligned" with the values of the community, protectors and promoters of these values (pg. 189).

The main objective of the school would be to preserve the purity of the culture, this could lead to a dangerous position if there are complaints of cultural differences for one community with regards to another, and then diversity is denied and these differences are transferred to the free and autonomous citizens.

\section{The idea of diversity in civic republicanism}

It is important to note that even though there are dangers in communitarianism, it reminds us that the individual exists and lives within a social context and not as an abstract or impersonal entity, which leads not only to a quest for freedom, but a need to construct solid bonds with the people that they are surrounded by.

Nevertheless, in the thesis, republicans, that Sacristan (2002) presents, culture is not the only form of social integration that is possible, beyond the cultural aspect, according to this author political integration referred to civitas, the State, is possible. The character of the State is more abstract and covers every citizen, assuring the loyalty of a shared 'political culture'. This idea of political integration rests of the conviction that it is possible to aspire for the common good, as an absolute and universal value. 
URL: http://www.una.ac.cr/educare

CORREO: educare@una.cr

In democracy, the possibility of this political community, in some fashion, annihilates differences, even the cultural diversity of its citizens, but democracy affirms that beyond our plurality, a shared project of social justice and freedom must be organized. Within this context the State sees itself as neutral, but conceptualizes society as plural. In other words, within the same political framework there can be co-existence of human groups that are cultural, linguistic and ethnologically diverse.

The ideal of political neutrality assures the respect of cultural singularities, but it also protects the freedom of individuals to choose values and customs that differ from those that characterize their community. This respect towards cultural diversity and individual freedom must be within the limits demanded by the construction of a common moral, civic and political project.

The objective is not to deny diversity its value, but simply accept it in its rightful dimension. When confronted with the right to diversity, the need of co-existence and interdependence must be present so that dialogue may be possible. This dialogue will involve universal ethics in communication procedures and meanings, which without doubt, must be pluralistic.

This entails important implications for education because at one end it must faithfully reflect an open society and, as Sacristan (2002) states, allow individuals to make cultural decisions with all the choices available, so that the individual can model his subjectivity, without being controlled by family, church or school.

At the other end, this education must be a promoter of alternatives, models of human beings and society, which is reflected in the curriculum that is a valued selection of the culture. Therefore, although the education system must be flexible enough to include the mix of cultural differences, or other differences, which co-exist in political society, it must go further, positioning the person in a situation in which they are capable of using their freedom of thought so that, through criticism, they can rebuild their environment, always seeking the edification of a more just, free and equal society. With regards to this Sacristan (2002) expresses that the school is an inevitable and necessary reproduction apparatus of society and the dominant cultures, but that it can be and has been a reconstruction instrument for both, if supported by an adequate project and develops it coherently.

Even though recognizing diversity responds to a profound human need, we cannot infer that from this recognition there must exist different education for different groups and subjects. The same goes for seeking a common project; we cannot revalidate the homogeneous theory and practice of modern education. Sacristan (2002) considers that: "The common curriculum derived from the illustrated presumption that certain universality exists and is convenient, is compatible with the right to a different curriculum, which also derives from the illustrated thought. In every classroom, every school and throughout the entire education system spaces need to be provided for different cultural alternatives so that there may be a differentiation that does not discriminate anyone" (pg. 245). 
Definitively, for the thesis of the republicans, the common curriculum must be the correlation between modern societies, which are characterized as being complex, everchanging and the result of intense cultural exchange that intertwine them. Even though it is thought that the curriculum is culturally relevant, a diversity curriculum must go beyond culture, allowing humans to criticize their environment and facilitating the development of the necessary authorities to build a project for society that not only assures the individual freedom to be different, but to integrate in a solidarity framework with his peers.

\section{The political relevance towards the diversity concept and the political vocation of education for diversity}

When faced with this posture regarding the social model that can be seen as desirable, it can be said of the diversity concept, in a certain manner, it is an unambiguous idea, much less innocent. Not only are there multiple ways to understand and assume diversity, but the view we adopt will respond to a certain ideological vision of the political community.

The diversity concept, from a critical standpoint, redefines difference, understanding that which is important as a product of power. Bhabha (cited by Giroux, 2001) writes the following:

The idea that cultural diversity constitutes a problem, due to the fact that there already exist many different cultures is not the reason that cultural difference exists. Cultural difference is an elaborated discourse when elements of power or authority are being defied (...). Cultural difference is not difficult, because there are different cultures, but because there is a particular matter regarding the redistribution of goods among the cultures or the funds of the cultures (...) (pg 71).

With this in mind, a discourse that admits the political relevance of diversity, should essentially be protesting against inequality imposed by relations and structures of the social powers.

It is also noteworthy to mention the possibility of elaborating a specific pedagogy, or, as it is generally known, an education for diversity. It is not possible to admit to a protest stance regarding education and not experience repercussions towards a redefinition in the mission of the education task. Therefore, the aim of education should go beyond the transmission of knowledge, and in this way reposition itself towards the reconstruction of social implications that deal with the differences being encountered.

Then, the educator, revalued and empowered as an agent of social change, will assume the task, according to McLaren (1997), of questioning the placement, positioning and the specificity of knowledge (in terms of placement of race, class and gender of the students), and to generate a plurality of truths, while establishing the construction of meanings in terms of material interests, those that work in the production of forms of intelligibility and social practices. 
URL: http://www.una.ac.cr/educare

CORREO: educare@una.cr

An education for diversity is not exhausted in the aspiration, established in the Jomtien Declaration (1990), in spite of the nobility of the idea to guarantee each person the real possibility to access and survive within the education system. It is clear that an education for diversity must take ownership with regards to the concern expressed in Jomtien, to suppress the educational barriers that can hinder that the so-called neglected groups can take advantage of the educational opportunities. These neglected groups are constituted by: the poor, children of the street, child workers in rural areas, nomads, migrants, indigenous and minority populations.

Nevertheless, education for diversity must go even further and be constituted as an instrument in the formation of a critical citizen ship that knows how to read their diverse condition and propose solutions in order to access to higher levels of equality. At this point, it is worth mentioning the idea of Giroux (2001), that political education allows the students to express themselves in a critical manner and modify the participative structure and the horizon of debate in which their identities, values and desires are constructed. A political education establishes the pedagogical parameters that allow students to understand how power can influence their lives, how they influence with power and in which way they can use it, to consolidate and widen the role of critical citizens.

In this manner, the anthropological ideal of a curriculum for diversity should contemplate a citizen with the sufficient cognitive and epistemological power to critically review their identity, understanding the power and domination relations that have contributed to its resolution, providing new meanings and value. In this same manner, the citizen must possess the necessary emotional and intellectual competency to understand the identity of another person, their historic and political situation, and be able to propose new formulas of equality and coexistence in relation to the other person.

\section{The problem of diversity for pedagogy}

At some point, the education doctrine has defined the challenge of diversity as the possibility, of the entire alumni, to access the curriculum, accepting the differences at every level, trying to provide just educational answers and appropriate to the suggested needs. Recognizing the existing diversities constitutes the starting point to avoid that the differences turn into inequality and disadvantages among individuals (Belmonte, 1998).

This manner of facing the challenges of diversity has significant consequences. First, it recognizes different variables of diversity, even beyond the cultural aspect, such as: capacity, learning styles, learning rhythm and motivations. Second, this form of understanding diversity demands a strategic review (methodological) regarding how to attend diversity. According to Belmonte (1998), in this manner, at least two main ideas are conceived: 
- The elaboration of distinguishing strategies that try to share and respect differences, promoting them, when possible, and

- An equal and centripetal elaboration that attempts to compensate and overcome inequalities.

In this approach, the objective for diversity is the pedagogy centered in the person learning as well as the formation of the person teaching, with the capacity to not create institutional segregation (Devalle and Vega, 1999).

Therefore, in these terms, the challenge of diversity is to allow everyone access to the curriculum. But, what are the consequences of recognizing diversity as a dynamic and political concept, an identity that is conceived from the asymmetrical power relations?

The answer is clear. An education that understands the unjust reality that has given way to the construction of the so-called diverse identities, identities constructed upon factors dealing with differences, should be capable of questioning the political assumptions and the decisive factors upon which social truths are founded, in communities where these apply as well as in society in general (McLaren, 1997).

This is a pedagogy of solidarity which allows individuals to reevaluate the meanings that they have based their identity upon, be that a non diverse identity or a diverse one, to develop new ties of social solidarity, and therefore, rebuild their identities. The aim of this pedagogy is the formation of a critical citizen, a "pluralized and hybrid" citizen, as intended by McLaren (1997), that can bravely and intelligently recognize the need to amend the injustices that underlie in the formation of diverse identities, to build new meanings that allow the construction of new power relations and structures, much more equal.

This implies that an education for diversity needs to go beyond a strategic or methodological change and demand the reconstruction of a curriculum, starting with a thorough review of the anthropological and social fundamentals that sustain the curriculum, modifying objectives and contents, not to create differences that result in new methods of separatism (McLaren 1997), but in efforts to design an educational policy that allows the birth of new citizens that aspire freedom from oppression and social exclusion.

\section{Basis for a conceptual proposal}

If we accept what was mentioned in the previous section, it is evident that many differences exist among human beings. Taking this into account it can be said that disparity is an inherent condition in human nature. Nevertheless, although it is obvious that we can find elements that differentiate us, we can also find elements that share similar traits and unite us. It is also important to 
URL: http://www.una.ac.cr/educare

CORREO: educare@una.cr

underline that not all differences are problematical. There are differences, like that of right handed and left handed people, that currently does not pose any significant problem (Hernández 2005).

We must also recognize that the diversity concept is characterized by its relative and open nature. It is a concept that changes depending on the historic setting. In the example shared above, the truth being said, no significant bearing results from the difference between right handed and left handed people, but a few decades ago being left handed was a very serious problem, at least within the educational process.

Therefore, in order to define the basis for a conceptual proposal it must be clarified that not all differences are of interest, only those that due to their power relations and structures are cause for exclusion.

Even though diversity concepts and those of exclusion cannot be understood as synonyms, the kind of diversity that is truly problematic is that which is associated with phenomenons of exclusion. The problem of diversity lies in the fact that given its centralized and homogeneous character of power in politics within our societies, the diverse communities (in comparison to the central or national identity) have been excluded from the political procedures, including the educational process.

With regards to the educational process it is best to clarify that the exclusion of diversity is expressed through two important methods:

a. When a specific community is hampered, or in the worst case scenario, they are denied access to education.

b. When a specific community is excluded from the curriculum because their identity is not found represented, and they are subjugated by the education system that actively promotes the official identity.

Pedagogy for diversity should attend a historical claim from diverse communities to be included within the curriculum and in the educational process as a whole.

Using this analysis of the diversity concept from a pedagogy perspective as a basis, we can outline characteristics for a diversity curriculum, such as the materialization of this proposal for a new pedagogy.

\section{A curriculum for a democratic citizenship}

The articulation of an education policy that attends diversity is necessary; it pairs up with the grave risk of curricular fragmentation. Attending diversity should not attempt to hide the communities that are different, in educational ghettos, with closed curriculums specifically designed for them. 
According to Savater (2002), what really threatens us again today is returning to the origin as an inexorable condition in the way we think: divide the world in stagnant ghettos of an intellectual nature. In other words, only people of a specific nation can understand others from that nation, or only blacks can understand other blacks, only asians can understand other asians, only white people can understand other white people, only christians can understand other christians, only muslims can understand other muslims, only women can understand other women, only homosexuals can understand other homosexuals and only heterosexuals can understand other heterosexuals. Each tribe must remain closed, identical to the identity established by their patriarchs or cacique, absorbed by the purity of their own crowd. Therefore, there must be a different education for each one of these groups so that they respect it, in other words, to confirm their prejudice and which does not allow them to open up and be transformed alongside everyone else.

On the contrary, according to Hernández, Ibarra and Quesada (1993), a diversity curriculum would have to be open and plural, essentially characterized by providing the necessary space for all identities, but also to provide opportunities to recognize the universality that unites us all as humans and members of a political community, consequently providing value to the relationships and exchanges between different communities. Of course, none of these identities should be attributed to themselves; a central thought in the curriculum.

The proposed curriculum aspires toward the elaboration of a political identity (De Lucas 2003) that preserves the value of the cultural identity without monopolizing the democratic identity. The end objective of the curriculum is the formation of a democratic citizenship, where multiple identities are found, all in equal terms.

Consequently, within this curriculum, integration and inclusion are not conceived as an assimilation process, but as a political-democratic integration process. This is vital since a pedagogy of diversity must also promote coexistence contexts that allow distinct communities to build a common project within a framework of plurality.

\section{A curriculum for inclusion}

It is convenient to establish that the proposed curriculum must not merely admit diversity, but should be oriented towards diversity, for diversity. This type of diversity education should not only be a theory, it must be a necessary practice, because it is not about tolerating difference, but valuing difference as the factor that influences learning procedures (Devalle and Vega, 1998).

As these authors point out, when dealing with the elaboration of an education for diversity, it is important that the school does not confront diversity as if it were an accident, but it is imperative that the school be aware that diversity is an intrinsic characteristic of the social-cultural and 
URL: http://www.una.ac.cr/educare

CORREO: educare@una.cr

political context in which it is immersed. The objective is to transform the current paradigm, which is viewed as disadvantageous or deficient, and build it upon a value that guides the educative action in the direction of principles based on equality, justice and freedom.

In conclusion, paraphrasing Devalle and Vega (1998), this school for diversity is the characteristic of a democratic society that has incorporated in their State projects the relentless objective to guarantee every person (understanding that all human beings are diverse) the right to an education. In other words, a diversity curriculum should not only attempt to offer education for multiple identities that coexist within the same social-political context, but it must also attempt to guarantee universal access to education, removing any and all obstacles that might exist so that diverse communities or individuals can access the same education.

\section{A curriculum to redefine identities}

A diversity curriculum, along with being open to multiple identities present in society, must also include as one of its objectives the redefinition of identities.

If the aim of the curriculum is to truly contribute in the formation of a democratic citizenship, the curriculum must allow a critical review of the diverse identities and also of the so-called official identity. The goal is to abandon any idea related to a centralized and State supremacy identity. Another goal is to reclaim the right of the communities to visualize their identities within the same pedagogical process, without implying an idealization of these identities, but rather seen from a reconstructive and critical perspective.

It is understood that the review of multiple identities must be performed in a context of dialogue and exchange between the communities. In other words, the objective is not to repeat the monolithic essentialism of centrism, but to recognize that the value of our identity is correlated to the value of others. McLaren (1997) believes that the need to create a policy of allegiance and construction, to dream together, to demonstrate solidarity that goes beyond affability must be won in the struggle. He believes this is not centered on the imperatives of the market, but is developed from the imperatives of freedom, democracy and a critical citizenship.

Therefore, the process of redefining identities should be fulfilled within a community framework and that of solidarity, to facilitate the redefining to take place, but also the possibility to build a common project with the identities. A project that is developed based on a hybrid citizenship concept, which is not associated with our State supremacy identity - a Catholic, Spanish speaking mestizo from Costa Rica -, and is able to integrate with a common project whose protagonists are every single identities of the country.

\begin{tabular}{l|l}
\hline 12 & Dora Hernández Vargas
\end{tabular}

Los artículos de la Revista Electrónica Educare del Centro de Investigación y Docencia en Educación de la Universidad Nacional, Costa Rica, se comparten bajo términos de la Licencia Creative Commons: Reconocimiento, No Comercial, Sin Obra Derivada 3.0 Costa Rica. Las autorizaciones adicionales a las aquí delimitadas se pueden obtener en el correo: educare@una.cr 


\section{A curriculum for the transformation of reality, towards a more just reality}

In conclusion, it is necessary to emphasize that the diversity challenge is not only limited to assuring the right to education for the diverse communities. For this reason, the pedagogical answer cannot be exclusively limited to the pedagogical individualization. The diversity challenge is imbedded with an intense connotation for justice, and consequently demands a deep curricular reform that touches all its factors and elements. A reform that transforms the curriculum into an open instrument for all identities from the diverse communities of society, and provides the necessary setting for the review of those identities; a review that provides freedom for the imposed conditioning by the imbalance of the ruling power.

Notwithstanding the foregoing, this is also a proposal for solidarity that invites different subjects to review their identity, within a setting of dialogue and reflexiveness, so that the redefinition can take place in a constructive and critical manner. Finally, the objective of this proposal is the formation of a new citizen concept, citizens that recognize themselves as part of a specific collective group or groups and at the same time as part of a democratic and supportive project.

\section{Final thoughts}

One of the main thesis of this study is that the education system is a key factor in the formation of identities, in the same manner that the formation of the national Costa Rican State outlined and consolidated the Costa Rican nationality, destroying any other imaginable identity in our country.

The objective of the conceptual proposal is to reclaim the curriculum as a public enterprise, to rethink and rebuild the identities it serves. We must remember that diversity is always constituted in relation to another point of reference: you are diverse "with regards to". An ability to keenly discern is needed and an adequate sensibility to understand which diversities complement and enrich us as individuals and as a community, and which diversities exclude and segregate us. The pedagogical task should assist us to and demand that we develop these abilities.

\section{References}

Belmonte, M. (1998). Atención a la Diversidad. Diseño de Estrategias y evaluación formativa basada en el análisis de tareas. Tomo I. Bilbao: Ediciones Mensajero.

De Lucas, J. (2003). Globalizacion e Identidades: Claves politicas y jurídicas. Barcelona: Icaria Editorial.

Devalle, A. y Vega, V. (1999). Una escuela en y para la diversidad. El entramado de la diversidad. Buenos Aires: AIQUE. 
URL: http://www.una.ac.cr/educare

CORREO: educare@una.cr

Giroux, H. (2001). Cultura, política y práctica educativa. Barcelona: Graó.

Hernández, D. (2005). The diversity concept in the current educational process in the Study plan and the course program for the Masters in Pedagogy with emphasis in diversity in the educational process from the Universidad Nacional. Final work for the courses: Didactics for the construction of knowledge and Pedagogical analysis of diversity. Masters in Pedagogy with emphasis in diversity in the educational process. Heredia, Costa Rica: Universidad Nacional.

Hernández, O., Ibarra, E. y Quesada, J. R. (1993). Discriminacióny racismo en la historia costarricense. San José: Editorial de la Universidad de Costa Rica.

McLaren, P. (1997). Critical Pedagogy and Predatory Culture: Oppositional Politics in a Postmodern Era. (Spanish Edition: Pedagogía crítica y cultura depredadora. Políticas de oposición en la era posmoderna). Barcelona: Ediciones Paidós.

Sacristán, J. G. (2002). Educar y convivir en la cultura global. Madrid: Editorial Morata.

Savater, F. (2002). El valor de educar. Barcelona: Ariel. 